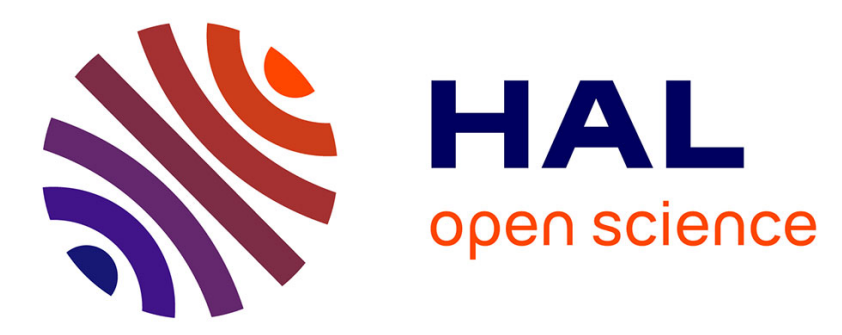

\title{
Improved transparency-nonlinearity trade-off with boroxine-based octupolar molecules
}

Gilles Alcaraz, Lisenn Euzenat, Olivier Mongin, Claudine Katan, Isabelle Ledoux, Joseph Zyss, Mireille Blanchard-Desce, Michel Vaultier

\section{- To cite this version:}

Gilles Alcaraz, Lisenn Euzenat, Olivier Mongin, Claudine Katan, Isabelle Ledoux, et al.. Improved transparency-nonlinearity trade-off with boroxine-based octupolar molecules. Chemical Communications, 2003, 22, pp.2766-2767. 10.1039/B308664J . hal-01416740

HAL Id: hal-01416740

https://hal-univ-rennes1.archives-ouvertes.fr/hal-01416740

Submitted on 14 Dec 2016

HAL is a multi-disciplinary open access archive for the deposit and dissemination of scientific research documents, whether they are published or not. The documents may come from teaching and research institutions in France or abroad, or from public or private research centers.
L'archive ouverte pluridisciplinaire HAL, est destinée au dépôt et à la diffusion de documents scientifiques de niveau recherche, publiés ou non, émanant des établissements d'enseignement et de recherche français ou étrangers, des laboratoires publics ou privés. 


\title{
Improved transparency-nonlinearity trade-off with boroxine-based octupolar molecules $\uparrow$
}

\author{
Gilles Alcaraz, ${ }^{a}$ Lisenn Euzenat, ${ }^{a}$ Olivier Mongin, ${ }^{a}$ Claudine Katan, ${ }^{a}$ \\ Isabelle Ledoux, ${ }^{b}$ Joseph Zyss, $^{b}$ Mireille Blanchard-Desce ${ }^{* a}$ and Michel Vaultier* ${ }^{a}$ \\ ${ }^{a}$ Synthèse et ElectroSynthèse Organiques (CNRS, UMR 6510), Université de Rennes 1, Institut de \\ Chimie, Campus Scientifique de Beaulieu, Bât 10A, F-35042 Rennes Cedex, France. E-mail : \\ Mireille.Blanchard-Desce@univ-rennes1.fr \\ ${ }^{b}$ Laboratoire de Photonique Quantique et Moléculaire (CNRS UMR 8537), ENS Cachan, \\ 61 avenue du Président Wilson, F-94235 Cachan Cedex, France
}

\begin{abstract}
A series of octupolar molecules derived from the boroxine framework were designed and their optical nonlinearities were investigated by performing harmonic light scattering experiments in solution; the molecules were found to combine excellent transparency in the near $\mathrm{UV}$-visible region $\left(\lambda_{\max } \leq 280 \mathrm{~nm}\right)$ and significant first-order hyperpolarisabilities (up to $\beta(0)=5610^{-30} \mathrm{esu}$ ).
\end{abstract}

The field of molecular nonlinear optics (NLO) has attracted increasing interest over the past twenty years, owing to its connection with fundamental issues such as charge transfer, higher order polarisabilities or conjugation, as well as to numerous applications in various fields such as telecommunications, ${ }^{1}$ optical data storage, ${ }^{2}$ microfabrication, biological imaging... Within this framework, organic chromophores have received major attention owing to their chemical flexibility. For instance, molecular engineering of "push-pull" compounds has proven particularly successful leading to chromophores displaying record first $(\beta)$ and second $(\gamma)$ hyperpolarisabilities. Yet, these chromophores are plagued by an intense absorption in the near-UV-visible region that significantly restricts their transparency range. Novel strategies were thus needed for optimising the efficiency-transparency trade-off.

Octupolar molecules, with 1,3,5-triamino-2,4,6-trinitrobenzene (TATB) as the prototypical structure, provide an interesting alternative for this purpose. ${ }^{3}$ Following this approach, a variety of organic molecules with a two-dimensional (2D) character of $\beta^{4}$ as well as several 3D octupolar molecules ${ }^{5}$ have been designed and investigated in recent years. ${ }^{6}$ Within this context, we have investigated a series of original and transparent octupolar molecules built from the boroxine ring. Their molecular design is based on the symmetrical grafting of three donating appendices on the electron-deficient boroxine core (Scheme 1). The boroxine ring usually leads to quasi planar structures, ${ }^{7}$ a common feature with triazines whose octupolar derivatives have been widely studied. ${ }^{4 b, \mathrm{~d}-\mathrm{f}}$ In contrast, boroxine shows much lower aromatic character. ${ }^{8}$ We emphasize that although boron inorganic derivatives have long been known to display interesting NLO properties, $\$$ the potentialities of organic boroxine derivatives for NLO have not been considered yet.

Phenyl units were used as rigid links between the electronreleasing substituents and the boroxine core. Peripheral groups with increasing donating character were used with the aim of tuning the optical properties. Triarylboroxine derivatives are usually obtained from the corresponding boronic acids via a cyclocondensation reaction leading to the cyclic trimeric anhydride. We have implemented an innovative route that allows

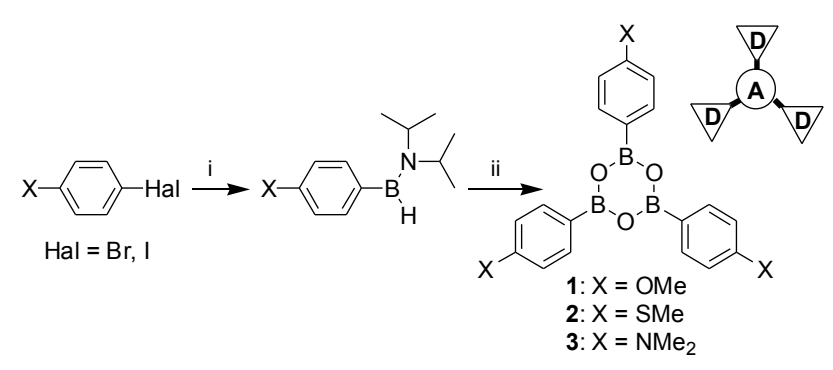

Scheme 1 Reagents and conditions: i, $i-\mathrm{Pr}_{2} \mathrm{NBH}_{2}$ (2 equiv.), $\mathrm{Et}_{3} \mathrm{~N}$ (5 equiv.), $\mathrm{Pd}^{(0)}(5 \mathrm{~mol} \%)$, dioxane, $15 \mathrm{~h}, 78^{\circ} \mathrm{C}$; ii, $\mathrm{H}_{2} \mathrm{O}$ (1.5 equiv.), 16h, rt.

an efficient and versatile preparation of triarylboroxines via the borylation/hydrolysis sequence of $p$-substituted aryl halides 9 (Scheme 1). The presence of electron-donating substituents has been reported to increase the stability of triorganoboroxine derivatives towards hydrolysis. ${ }^{10}$ All the derivatives investigated in the present study have been fully characterized by NMR, HRMS and elemental analysis prior to their optical study. X-Ray diffraction from single crystals of $\mathbf{1}$ shows that this molecule is quasi planar with the three phenyl rings lying approximately in the plane of the boroxine ring (Fig. 1).

The absorption characteristics of the series of derivatives 1-3 are gathered in Table 1. The molecules show an intense

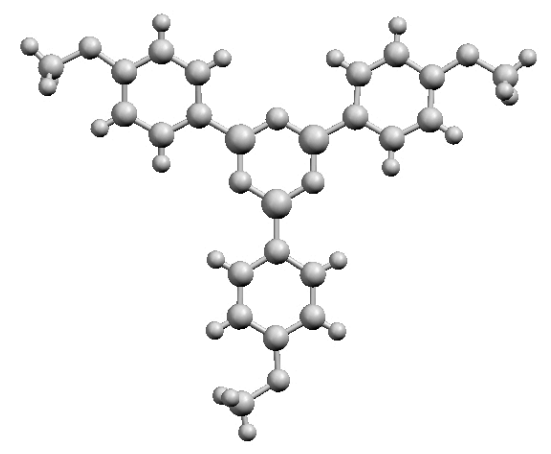

Fig. 1 X-Ray structure of boroxine derivative 1.

absorption band in the UV region but maintain full transparency in the near UV-visible region. A slight positive solvatochromism is observed, indicative of a larger stabilisation of the excited state as compared to the ground state by a polar solvent. Increasing the donating strength of the substituents leads to a broadening and a bathochromic and hyperchromic shift of the absorption band and to a more pronounced solvatochromism. 
Table 1 Absorption and nonlinear properties of molecules 1-3 in chloroform

\begin{tabular}{cccccccc}
$\begin{array}{c}\text { Comp } \\
\mathrm{d}\end{array}$ & $\begin{array}{c}\lambda_{\max } \\
(\mathrm{nm})\end{array}$ & $\begin{array}{c}\varepsilon_{\max } \\
\left(\mathrm{M}^{-1} \cdot \mathrm{cm}^{-1}\right)\end{array}$ & $\begin{array}{c}\mathrm{FWHM}^{a} \\
\left(\mathrm{~cm}^{-1}\right)\end{array}$ & $\begin{array}{c}\lambda_{\text {cut-of }} \\
(\mathrm{nm})\end{array}$ & $\begin{array}{c}\Delta v^{b} \\
\left(\mathrm{~cm}^{-1}\right)\end{array}$ & $\begin{array}{c}\beta_{\mathrm{HLS}} \\
\left(10^{-30} \mathrm{esu}\right)\end{array}$ & $\begin{array}{c}\beta_{\mathrm{HLS}}(0) \\
\left(10^{-30} \mathrm{esu}\right)\end{array}$ \\
\hline $\mathbf{1}$ & 241 & $4.010^{4}$ & 1750 & 286 & - & 47 & 35 \\
$\mathbf{2}$ & 270 & $4.6 .10^{4}$ & 3360 & 301 & 69 & 45 & 31 \\
$\mathbf{3}$ & 281 & $5.8 .10^{4}$ & 4350 & 326 & 450 & 83 & 56 \\
TIATB & 375 & & & & & 10 & 4.4
\end{tabular}

${ }^{a}$ Halfbandwith. ${ }^{b}$ Solvatochromic shift $=1 / \lambda_{\max }\left(\mathrm{CHCl}_{3}\right)-1 / \lambda_{\max }(\mathrm{DMSO})$.

Interestingly, HOMO-LUMO calculations reveal an intramolecular charge density shift from the donating appendices towards the boron atoms (Fig. 2).

The first hyperpolarisabilities $\beta$ have been determined by
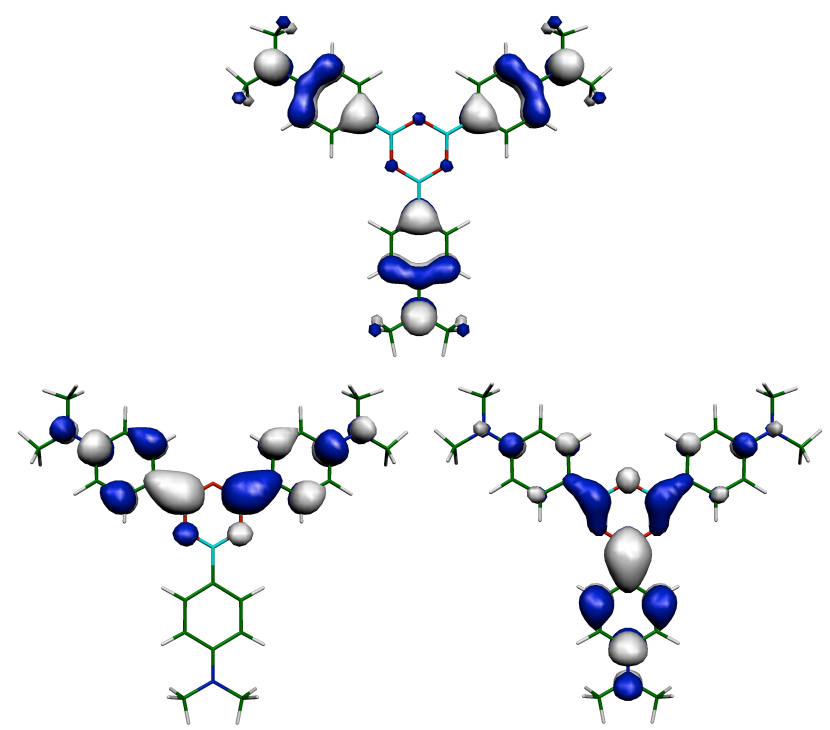

Fig. 2 Contour surfaces of HOMO (up) and degenerated LUMO, LUMO+1 (down) of organoboroxine 3 .

performing harmonic light scattering (HLS) experiments in solution, which yield the HLS molecular averaged hyperpolarisability $\sqrt{\left\langle\beta^{2}\right\rangle}=\beta_{\text {HLS. }}{ }^{11}$ HLS experiments were performed at $1.064 \mu \mathrm{m}$ locating the second harmonic signal in the transparency region.\# The corresponding static values $\beta_{\mathrm{HLS}}(0)$ are calculated using a degenerated three-level dispersion factor. ${ }^{3 \mathrm{~b}}$ The experimental values are compared to those reported for TIATB, ${ }^{4 a}$ a soluble analogue of TATB, using the $\beta^{\mathrm{X}}$ convention. ${ }^{12}$

Examination of the series of molecules indicates that increasing the donating strength of the substituents results in a significant enhancement of $\beta$. Molecule 3 which bears the strongest electron-releasing subsituents of the series displays a molecular optical nonlinearity nearly twice larger than molecule 1, providing evidence that intramolecular charge transfer influences the nonlinear responses. We note that such boroxine derivative indeed leads to an improved efficiency-transparency trade-off as compared to triazine or TATB octupolar derivatives: molecule 3 displays a $\beta(0)$ value about one order of magnitude larger than TIATB while remaining blue-shifted by nearly 100 $\mathrm{nm}$ and having a molecular weight less than twice larger.

Finally, our study demonstrates that the functionalisation of the boroxine core provides a promising and innovative route for the optimisation of the nonlinearity-transparency trade-off. It also opens the way for further engineering of the optical nonlinearity by boosting the multidimensional intramolecular charge transfer between the core and the peripheral groups. ${ }^{4 h, i}$
This work was supported by the GDR MATFON. The calculations have been supported by CINES-France. We are grateful to T. Roisnel for X-rays diffraction experiments.

\section{Notes and references}

$\dagger$ Electronic supplementary information (ESI) available: Characterization data and UV-Visible spectra for compounds 1-3; computational details. See http://****

$\pm \quad$ Such as BBO, used in wavelength conversion devices.

$\S$ Crystal data for 1: $\mathrm{C}_{21} \mathrm{H}_{21} \mathrm{~B}_{3} \mathrm{O}_{6}, \mathrm{M}=401.81$, monoclinic, space group $\mathrm{P} 2{ }_{1} / n, a=9.0568(2), b=14.1334(4), c=16.9564(7) \AA, \beta=$ $104.5710(10)^{\circ}, V=2100.67(11) \AA^{3}, Z=4, T=293(2) \mathrm{K}, D_{\mathrm{c}}=1.271 \mathrm{~g}$ $\mathrm{cm}^{-3}, R_{1}=0.0502, w R_{2}=0.1184$ for $I>2 \sigma(I)$. See http://**** for crystallographic data.

- The corresponding transition are symmetrically allowed and the calculated energy gaps (242 nm for 1, $268 \mathrm{~nm}$ for 2, and $269 \mathrm{~nm}$ for 3) show good agreement with the values derived from the absorption spectra for the lowest energy transition (Table 1).

\# This procedure avoids possible contamination of the HLS signal by two-photon excited fluorescence. In addition, the boroxines 1-3 did not show any detectable fluorescence when excited in their absorption band.

1 (a) M. Ahlheim, M. Barzoukas, P. V. Bedworth, M. BlanchardDesce, A. Fort, Z.-Y. Hu, S. R. Marder, J. W. Perry, C. Runser, M. Staehelin and B. Zysset, Science, 1996, 271, 335; (b) Y. Shi, C. Zhang, H. Zhang, J. H. Bechtel, L. R. Dalton, B. H. Robinson and W. H. Steier, Science, 2000, 288, 119.

2 D. A. Parthenopoulos and P. M. Rentzepis, Science, 1989, 245, 843.

3 (a) I. Ledoux, J. Zyss, J. S. Siegel, J. Brienne and J.-M. Lehn, Chem. Phys. Lett., 1990, 172, 440; (b) J. Zyss and I. Ledoux, Chem. Rev., 1994, 94, 77.

4 (a) T. Verbiest, K. Clays, C. Samyn, J. Wolff, D. Reinhoudt and A. Persoons, J. Am. Chem. Soc., 1994, 116, 9320; (b) P. C. Ray and P. K. Das, Chem. Phys. Lett., 1995, 244, 153; (c) S. Stadler, C. Bräuchle, S. Brandl and R. Gompper, Chem. Mater., 1996, 8, 414; (d) R. Wortmann, C. Glania, P. Krämer, R. Matschiner, J. J. Wolff, S. Kraft, B. Treptow, E. Barbu, D. Längle and G. Görlitz, Chem. Eur. J., 1997, 3, 1765; (e) V. Thalladi, R., R. Boese, S. Brasselet, I. Ledoux, J. Zyss, R. K. R. Jetti and G. R. Desiraju, Chem. Commun., 1999, 1639; (f) J. J. Wolff, F. Siegler, R. Matschiner and R. Wortmann, Angew. Chem., Int. Ed., 2000, 39, 1436; (g) C. Lambert, W. Gaschler, G. Noll, M. Weber, E. Schmalzlin, C. Brauchle and K. Meerholz, J. Chem. Soc., Perkin Trans. 2, 2001, 964; (h) J. Brunel, I. Ledoux, J. Zyss and M. Blanchard-Desce, Chem. Commun., 2001, 923; ( $i)$ B. R. Cho, S. B. Park, S. J. Lee, K. H. Son, S. H. Lee, M.-J. Lee, J. Yoo, Y. K. Lee, G. J. Lee, T. I. Kang, M. Cho and S.-J. Jeon, J. Am. Chem. Soc., 2001, 123, 6421; (j) B. R. Cho, K. Chajara, H. J. Oh, K. H. Son and S.-J. Jeon, Org. Lett., 2002, 4, 1703.

5 (a) C. Lambert, E. Schmälzlin, K. Meerholz and C. Bräuchle, Chem. Eur. J., 1998, 4, 512; (b) M. Blanchard-Desce, J.-B. Baudin, L. Jullien, R. Lorne, O. Ruel, S. Brasselet and J. Zyss, Opt. Mater., 1999, 12, 333; (c) C. Bourgogne, Y. Le Fur, P. Juen, P. Masson, J.F. Nicoud and R. Masse, Chem. Mater., 2000, 12, 1025; (d) G. P. Bartholomew, I. Ledoux, S. Mukamel, G. C. Bazan and J. Zyss, J. Am. Chem. Soc., 2002, 124, 13480.

6 For a recent and comprehensive review, see: E. Goovaerts, W. E. Wenseleers, M. H. Garcia and G. H. Cross in Handbook of Advanced Electronic and Photonic Materials and Devices, Ed. H. S. Nalwa, Academic Press, 2001, Vol. 9, p 127.

7 C. P. Brock, R. P. Minton and K. Niedenzu, Acta Crystallogr., Sect. C: Cryst. Struct. Commun., 1987, C43, 1775

8 (a) P. v. R. Schleyer, H. Jiao, N. J. R. v. E. Hommes, V. G. Malkin and O. L. Malkina, J. Am. Chem. Soc., 1997, 119, 12669; (b) P. W. Fowler and E. Steiner, J. Phys. Chem. A., 1997, 101, 1409.

9 L. Euzenat, D. Horhant, Y. Ribourdouille, C. Duriez, G. Alcaraz and M. Vaultier, Chem. Commun., 2003, in press.

10 Y. Tokunaga, H. Ueno, Y. Shimomura and T. Seo, Heterocycles, 2002, 57, 787.

11 (a) R. W. Terhune, P. D. Maker and C. M. Savage, Phys. Rev. Lett., 1965, 14, 681; (b) K. Clays and A. Persoons, Phys. Rev. Lett., 1991, 66, 2980.

12 A. Willets, J. E. Rice, D. M. Burland and D. P. Shelton, J. Chem. Phys., 1992, 97, 7590. 